\section{Comparison of spirometric thresholds in diagnosing smoking-related airflow obstruction}

The recent paper in Thorax by Bhatt et al ${ }^{1}$ asserted that using the lower limit of normal (LLN) for $\mathrm{FEV}_{1} / \mathrm{FVC}$ to define airflow obstruction in the diagnosis of COPD fails to identify a number of patients with significant pulmonary pathology that are identified by using a fixed ratio for $\mathrm{FEV}_{1} /$ FVC. However, they have not adequately proven that significant pulmonary pathology was being detected by using the fixed ratio. The authors first suggest that the LLN standard for defining airflow limitation from $\mathrm{FEV}_{1} / \mathrm{FVC}$ has not been clinically validated for lack of a gold standard. They then use CT-detected emphysema as a gold standard reference to judge various spirometry criteria. This approach is specious since there is no validated gold standard for CT defined emphysema. The authors concede in their article that 'there is no consensus on the cut-off for defining emphysema by quantitative CT'. Air spaces in the lungs of fit and healthy people get larger with age without destruction of alveolar walls, so this is not due to emphysema. ${ }^{2-4}$ Therefore, CT density thresholds for defining emphysema will need to adjust for the changes that just occur with age that are not due to a disease process (in a way similar to how lung function assessment using z-scores takes these age related changes into account). The authors have not done this.

The authors' abstract states that 'Subjects with airflow obstruction by fixed ratio only had a greater degree of emphysema than those by LLN only.' They use this to suggest LLN is missing patients with disease. Those few subjects $(n=18)$ abnormal only by LLN are known to include a predominance of younger women that the fixed ratio discriminates against (fails to diagnose true airflow limitation) and so being younger (mean age 47.2 years vs 65.3 years in the fixed ratio only group) they will have a different CT-density score. In younger people, it is likely airflow obstruction will arise from airway effects without so much emphysema. The important thing the authors fail to point out is that the substantial number of subjects $(n=548)$ who were abnormal by fixed ratio alone have much less 'emphysema' (LAA856exp 19.8 vs 38.8) than those positive by both LLN and fixed ratio $(n=2686)$. As others have found the 


\section{PostScript}

authors' data show that those identified by fixed ratio alone are quite different from those found by LLN and fixed ratio. The difference in CT scores (19.4 vs 10.9) between the discordant group $(n=566)$ and the normal group $(n=4491)$ was statistically significant but does not take into account that the normal group were on average 7 years younger and so this may just reflect changes due to age ${ }^{2-4}$ and not 'emphysema'.

The lower limits of normal for lung function have been derived using statistical techniques accepted worldwide by all scientific disciplines for looking at normal ranges of values within populations and are based on the data from tens of thousands of normal subjects aged 4-95 years. ${ }^{5}$ The same is not true for CT-density scores and so it is misrepresenting the facts of the matter to suggest a CT-density score can be used as a gold standard to validate a test of airflow obstruction and that LLN for lung function data have not been properly validated.

\section{Martin R Miller}

Correspondence to Professor M R Miller, Institute of Occupational and Environmental Health, University of Birmingham, Birmingham B15 2TT, UK;

m.r.miller@bham.ac.uk

\section{Competing interests None.}

Provenance and peer review Not commissioned; internally peer reviewed.

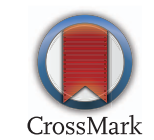

To cite Miller MR. Thorax 2014;69:1145-1146.

Received 17 July 2014

Accepted 14 August 2014

Published Online First 2 September 2014

\section{CLlinked}

- http://dx.doi.org/10.1136/thoraxjnl-2012-202810

- http://dx.doi.org/10.1136/thoraxjnl-2014-206089

- http://dx.doi.org/10.1136/thoraxjnl-2014-206123

Thorax 2014;69:1145-1146.

doi:10.1136/thoraxjnl-2014-205960

\section{REFERENCES}

1 Bhatt SP, Sieren JC, Dransfield MT, et al. Comparison of spirometric thresholds in diagnosing smokingrelated airflow obstruction. Thorax 2014;69:410-15.

2 Thurlbeck WM. The internal surface area of nonemphysematous lungs. Am Rev Respir Dis 1967;95:765-73.

3 Gillooly M, Lamb D. Airspace size in lungs of lifelong non-smokers: effect of age and sex. Thorax 1993;48:39-43.

4 Verbeken EK, Cauberghs M, Mertens I, et al. The senile lung. Comparison with normal and emphysematous lungs. 1. Structural aspects. Chest 1992;101:793-9.
5 Quanjer PH, Stanojevic S, Cole TJ, et al. Multi-ethnic reference values for spirometry for the 3-95-yr age range: the global lung function 2012 equations. Eur Respir J 2012;40:1324-43. 